\title{
The subversive conservationist
}

\author{
Pete Nowak
}

S ubversion is the process of attempting to change existing political structures or other forms of authority used to maintain the status quo. Subversive activities are those that work to overturn, or significantly alter, traditional ways of thinking about critical issues. How is it, you ask, that I can use subversive and conservationist in the same title? What does subversive have to do with being a conservationist?

Let me answer those questions by posing another simple question: As you look at the larger conservation community today, who speaks for soil and water resources? This simple question is rarely asked. However, when it is asked, the answer, more times than not, supports the need for subversion.

Listen and see if you hear what I hear when asking this question. I hear the modern equivalent of the Tower of Babel-many agency voices representing a multitude of programs, all based on the implicit assumption that more programs and more money means more conservation. Propagating agency jargon and acronyms and implementing accountability measures surrounding these efforts has become the focus of the many professional program managers who populate these agencies. Their dogma is simple: The more money they spend under various labels and titles, the more they believe they are advancing soil and water conservation. This implies that the only way to speak for soil and water resources is through a government check. Creativity is limited to defining different conditions under which a government check is issued. We have conditioned the last two generations of land users to believe that conservation means a government check, and now it appears that professional program managers have come to believe this dogma as well.

Pete Nowak is a professor of environmental studies in the Gaylord Nelson Institute for Environmental Studies at the University of Wisconsin-Madison, Madison, Wisconsin.
Here is an example: Farmers and ranchers elect local citizens to conservation district boards of directors. Those directors, in turn, view their role as one of bringing conservation dollars into the district, with little consideration given to actually solving conservation problems in the district. It all boils down to a process of seeing how many dollars can be acquired to induce or bribe individuals to participate in conservation programs. Program participation has become synonymous with conservation. Think about that last statement. This means many conservation programs are no longer a means to an end but the end in themselves. Professional program managers now dominate the ranks of traditional conservation agencies. These voices no longer speak for soil and water resources, but for agency budgets, program accountability, and management strategies that justify the status quo.

Let me ask again:Who speaks for soil and water resources? Voices from the scientific community are quick to offer a multitude of specialized treatises that advance disciplinary, institutional, or personal interests while subtly sidestepping the question of whether the science advances the conservation agenda. As in the case of program managers, conservation has become little more than an occupational area where one pursues a career. It is a context for science rather than the focal point of science. Funding is the primary concern for most scientists working in the conservation arena. Yet most funding is predicated on ideas fitting within an experimental plot methodology that reinforces a myopic spiral of outcomes that rarely addresses the realities of larger conservation systems. Those larger conservation systems involve communities of people, the surrounding biophysical resources, and the institutional context that surrounds both. For example, we typically ignore how the complex processes surrounding a conservation decision by a land user may be influenced by community norms and local culture. Instead, we treat those dynamic decisions about

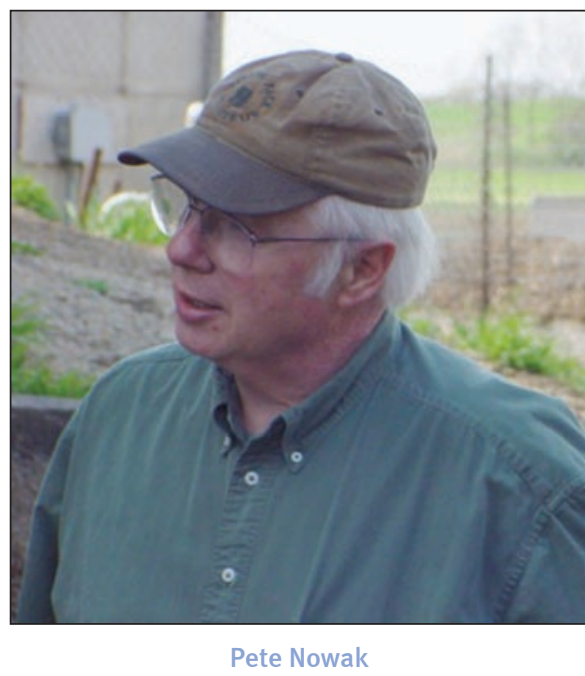

soil or water resources as if a simple, monetary accounting framework can represent them. That is easier and less "messy" than actually having to work with and listen to the complexities of real resource management decisions.

Speaking of the real, models and their underlying algorithms that are meant to parody but never reflect the real world have become the basis for most conservation initiatives. Rather than being used to guide development of creative and innovative responses to conservation challenges, models are now used to design programs, guide their implementation, and ultimately evaluate them. Forgive me, Marshall McLuhan, but the model has become the conservation message. Why study the significant variation in conservation practice when we can simply model the results we need to justify our current conservation programs. The so-called testing of models under different conditions and in different settings, coupled with the drive for peer-reviewed publications, has produced an endless iteration of unimaginative outcomes that have little applicability to the conservation challenges of today, let alone the looming challenges of tomorrow. Surely this cannot be the voice for soil and water resources!

Neither do I believe that many environmentalists speak for soil and water resources. 
We all recognize the type as they mount their white horses, adjust their blinders so as to look neither left nor right, and charge off to address their newest cause. Their goal is to employ assorted "chicken little" strategies to insure continued subscription to their particular brand of environmental dogma. Degradation of soil and water resources is not a problem, but rather an opportunity to raise more funds and build membership. Conservation is a means to an end, and the end has little to do with conservation. Over-simplification, overgeneralization, and other techniques for generating the right sound bite for television or a Web site is the voice I hear from this group.

Environmental groups, of course, have their corollary in the agricultural community when rhetorical claims by farmers about being the first environmentalists become muted when they bury their heads in the sand and ignore the degraded reality that surrounds them. They have become masters at appealing to agrarian ideals to gain public support for their policies while ignoring the distortion that those same policies exert on rural communities and landscapes. They often fail to represent the conservation ethics and values of the very people they supposedly stand for, but this does not stop them from seeking more public funds, with less accountability. These voices promoting their own selfinterest rather than speaking for soil and water resources are an integral part of the cacophony we now call the conservation community.

If managers of conservation programs, scientists, environmentalists, and agricultural leaders do not speak for soil and water resources, then who does? I would suggest that there is a minority of individuals in the conservation community who have earned the privilege to do so. They are the real conservationists, not the individuals who hold the occupational title of conservationist as they only manage programs and do things right. I am talking about that rare individual in today's conservation community who recognizes there is a critical difference between doing things right and doing the right thing. I am talking about those individuals who want to solve soil and water problems, not just manage programs. The very fact that the phrase "solving soil and water problems" is a radical concept in the context of today's programs speaks to the need for more subversive conservationists.

The subversive conservationist speaks for soil and water resources because her or his voice is predicated on having first listened to the land user, landlord, or manager of a local small business. This voice is not based on a field-office technical guide, strings attached to a government checkbook, what is on a computer screen at a local conservation office, or a complex empirical model. The voice is earned through performance, not bestowed on the basis of employment or occupational categories. A conservationist takes time to learn what soil and water conservation problems exist, where they exist, and why. Unfortunately, it is often viewed as subversive to believe that sustainable solutions must be based on an understanding of why a problem emerged in the first place.

Most importantly, the subversive conservationist understands that solving local soil and water problems can be risky. Rewards, recognition, and promotions go to those who manage programs well. Those who actually solve problems must be careful to avoid being labeled as subversive. We all know what organizational and agency program managers do to subversives.

My objective in writing this essay is to put forth the notion that we need more subversive conservationists in our community. We need to stop looking to national, state, or provincial capitals for solutions. Like politics, the solutions to most conservation problems are local. Distant agencies or elected officials may help us find assistance for viable solutions, but the solutions themselves will likely emerge from conservationists who understand local soil and water conservation issues-those subversive conservationists.

Remember that being subversive implies a willingness to change traditional patterns or ways of thinking about critical issues. Subversive ideas, such as rewarding agency staff for actually solving local conservation problems, deserve, at a minimum, more discussion. If we can experiment with paying producers for conservation performance, then isn't it hypocritical to expect less from agency employees who administer current conservation programs? Is it really so radical an idea to expect agencies who manage conservation programs to reward employees when they solve soil and water problems? Accountability is a necessity for any government program, but this can be carried to extremes, where the underlying programs become dysfunctional.

What about paying land users in small watersheds a proportionate incentive for working together to solve local conservation problems? The more local citizens who actively participate, the higher the incentive each receives. Why not be subversive and spend the available dollars in a way that uses peer pressure to advance conservation? Is being subversive really that wrong when one encourages neighbors to work with neighbors to solve local problems? It is important to remember that tillage clubs in the 1970s and pasture walks in the 1980s involved groups of neighbors who came together to promote the adoption of innovative conservation practices. No government agencies or universities could answer the questions those neighbors faced, and so they formed local groups to find the answers. Today, it seems to me, we have a choice of either listening to program managers rationalize why this approach won't work, or being subversive and designing means to entice groups of farmers and ranchers to collectively work to solve local resource management problems.

We also know that a relatively small amount of inappropriate behaviors in vulnerable locations or times create a disproportionate amount of the degradation in any watershed or other agricultural landscape. The subversive conservationist would argue for the need to address at the outset this small percentage of watershed area before moving on to "easier" or more receptive clients. Most recognize that this subversive idea is also common sense.

These ideas are not radical, but they are a different way of thinking about how we address soil and water conservation problems. 
Yes, I consider myself a subversive conservationist because I know we can do better if we apply the imagination and creativity that exists here and there in the conservation community. From Hugh Hammond Bennett's "magic lantern" shows in the Coon Creek watershed during the 1930s to the Web sites and blogs of today that promote nutrient trading schemes, we have stayed on message: We know you have a problem for which we have a technical solution that we will pay you to use. The subversive believes it is time to explore different messages.

There is no denying that use of government checks in conservation programs has achieved results. Many agricultural landscapes bear the mark of conservation because of the billions of dollars spent and the combined actions of governmental agency staff members, university faculty, and personnel associated with environmental and agricultural groups. However, any conservationist today will recognize that significant challenges remain and even more complex challenges are emerging in conjunction with globalization, urbanization, and climate change. Perhaps, it is time to stop idolizing H.H. Bennett and recognize that he was also a subversive conservationist in his own day when he chose a different path to address soil and water problems.

A premise of this essay is that continuing down the same narrow, rational path of the last 80 years may not be sufficient to address the challenges of today, let alone tomorrow. I am unwilling to take that chance. I would prefer to explore other, different ways of addressing those challenges. That action, however, puts me among the ranks of the subversive conservationists.
I'm convinced that it is their voice, not the droning cacophony described earlier, that really speaks for our soil and water resources 